\title{
Automatic household waste separation system based on resistance value and moisture content
}

\author{
Nurul Nazihah Ahamad, Sarah Yasmin Mohamad, Nur Shahida Midi, Siti Hajar Yusoff, Faridah \\ Abd Rahman \\ Department of Electrical and Computer Engineering, Kulliyyah of Engineering, \\ International Islamic University Malaysia, 53100 Kuala Lumpur, Malaysia
}

\begin{tabular}{l} 
Article Info \\
\hline Article history: \\
Received Jan 10, 2019 \\
Revised Feb 28, 2019 \\
Accepted Mar 20, 2019 \\
\hline
\end{tabular}

Keywords:

Automatic waste separation

Moisture content

Recyclable waste

Residual waste

Resistance value

\begin{abstract}
In the new era of globalization, waste disposal has turned into an immense concern among the nation. Nowadays, almost every part of the world is confronting a huge issue of improper disposal, segregation and recycling solid waste. Due to rapid growth in economy, industrialization and urbanization, there is also a rapid increase of capacity and volume of solid waste. As a result, improper management of solid waste lead to disturbance to the environment and human health. In this paper, a fully automated waste separation system to discriminate residual and recyclable waste is proposed. The system is designed to focus on household waste, since household waste ranks the highest volume of waste among others. It is designed to separate household waste into recyclable and residual waste according to the materials' state, which is dry and wet, by employing a moisture sensor to the waste separation system.
\end{abstract}

Copyright $@ 2019$ Institute of Advanced Engineering and Science. All rights reserved.

\section{Corresponding Author:}

Sarah Yasmin Mohamad,

Department of Electrical and Computer Engineering,

International Islamic University Malaysia,

53100 Jalan Gombak, Selangor, Kuala Lumpur, Malaysia.

Email: smohamad@iium.edu.my

\section{INTRODUCTION}

Due to rapid urbanization and increased population in many countries, a vast measure of waste has been produced [1]. The volume of solid waste produced over the world is relentlessly expanding. With each coming year, huge amounts of strong waste materials are added to the environment, mostly comes from the city, agriculture field and industrial field. To be precise, in Malaysia itself, Municipal Solid Waste (MSW) has generated more than $91 \%$ of waste over the past decade [2]. In 2001, an assessed 5.475 million tons of solid waste has been produced, which is around $0.81 \mathrm{~kg} /$ capita/day. On the other hand, in primary urban areas, the figure raised to $1.7 \mathrm{~kg} / \mathrm{capita} /$ day [2]. The World Bank's 2013 Report on Solid Waste documented that Malaysia has generated 21918 tonnes of solid waste per day, which was far above the global average. To curb this number, the government of Malaysia had implemented the "Separation at Source" program which were implemented from $1^{\text {st }}$ September 2015 onwards in a few states, where all premises are required to separate their solid waste to be collected by the municipal council. However, the implementation is still far from success. Malaysia is encountering quick industrialization and urbanization, giving the antagonistic impacts on the environments from the expanding of waste produced.

As we are concerned, residual wastes such as kitchen wastes are materials that are unable to be processed or treated for reuse in other form. During the past decades, Solid Waste Management-system (SWM) is being one of the consequential matters in many countries. In early days, waste is treated by utilizing four fundamental means, which consists of dumping/land fill, burning, recycling and waste minimization [1]. In the contemporary age, SWM has turned into an open administration framework where 
waste is handled through municipal expert [3]. The collection, transporting, processing, recycling and decomposition or final dispositions are parts of waste management.

In developing countries, solid waste has become a serious matter. Level of seriousness has been seen by numerous issues postured to nature and society, which ultimately affected the societal and individuals' great wellbeing and satisfaction [4]. Air pollution, water pollution, soil degradation and health concerns are the commonly dangerous effects that may occur due to the improper waste management. Pollution of air, water and soil occur due to unreserved decay of solid waste, may lead to the high volume of methane $(\mathrm{CH})$ and carbon dioxide $\left(\mathrm{CO}^{2}\right)$ from the landfilling into the air, which leads to global warming. Moreover, the discrimination of solid waste which is done manually by the labors may also expose them to hazardous diseases. Additionally, it is being less proficient, tedious and not totally practical because of the huge volume of waste.

Today, there have been quite a number of initiatives implemented to improve waste management system and to discriminate solid waste into its particular types and features. However, there are still shortcomings due to some reasons encountered. One of them is due to the attitude of men who refused to participate and practice waste sorting. It may cause the wastes to get mixed up and made it difficult for the labors to separate the waste manually. Apart from that, a number of technologies and researches being made to discriminate waste automatically in either domestic level or industrial level [5-13] still require improvements to increase the efficiency of a succesful automated waste separation system.

In this paper, a fully automated system that discriminate residual and recyclable waste is proposed. It is shown that the system are able to automatically separate waste into residual and recyclable waste by employing a moisture sensor to sort them into wet (residual) and dry (recyclable) waste. The state of the waste is determined by its resistance to current value and the percentage of water content.

\section{RESEARCH METHOD}

The system designed for this project uses the concept of a conveyor to move the waste into its respective bin; either dry waste bin (recyclable dustbin) or wet waste bin (residual dustbin). To operate this system, two sensors has been selected as the main subject; the ultrasonic sensor and the moisture sensor (FC-28). The ultrasonic sensor as shown in Figure 1 is used to detect the presence of waste by measuring the distance of an object by using sound waves. It measures distance by sending out a sound wave at a specific frequency and listening for that sound wave to bounce back. The range of distance for the ultrasonic sensor to detect a waste is between $0 \mathrm{~cm}-10 \mathrm{~cm}$. Basically, the ultrasonic sensor is used to notify the moisture sensor that there is a waste coming so that the moisture sensor is ready to obtain the resistance value and the percentage of water content of the waste.

In order to differentiate between wet waste and dry waste, a moisture sensor (FC-28) is used as the main component in this system. The moisture sensor as shown in Figure 2 is used to measure the dielectric permittivity of the waste by using the principle of capacitance. The sensor creates a voltage proportional to the dielectric permittivity. In this specific project, the dielectric permittivity is a function of the water content. Wet waste will have more water content compared to dry waste. Hence, the dielectric constant of wet waste will be more compared to dry waste. A current is passed across the electrodes through the waste material, and the resistance to the current in the material determines the water content. If the water content of waste is high, the resistance will be low, and thus more current will pass through. On the other hand, the resistance will be at high level when the water content of waste is low [5].

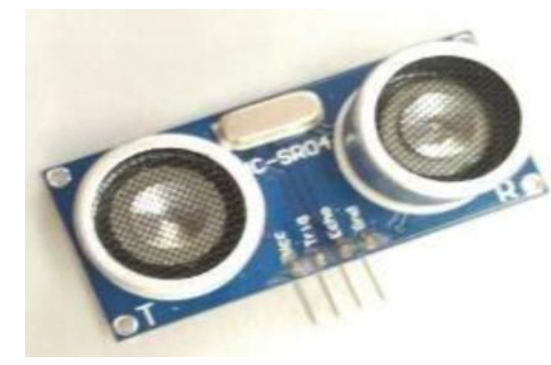

Figure 1. Ultrasonic sensor

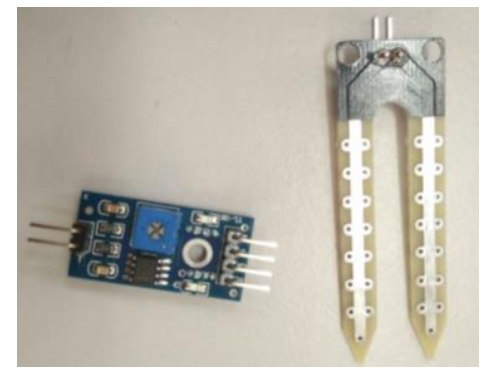

Figure 2. Moisture sensor (FC-28)

Next, Arduino Uno is used as the interface, where a coding is scripted into Arduino software to operate the system. This system will operate automatically right from the moment the waste is placed onto 
the conveyor until the end of the process where the system is able to distinguish the waste into dry waste (recyclable) or wet waste (residual).

Figure 3 shows the final prototype automatic waste separation system which is able to discriminate household waste into either residual or recyclable waste. It consists of an ultrasonic sensor, a moisture sensor, a $12 \mathrm{~V}$ DC motor, a servo motor and two dustbins. This system uses the concept of a conveyor belt to move the particular waste into its respective bin; either dry waste bin (recyclable dustbin) or wet waste bin (residual dustbin). To start, the conveyor is operated with the help of a DC motor.

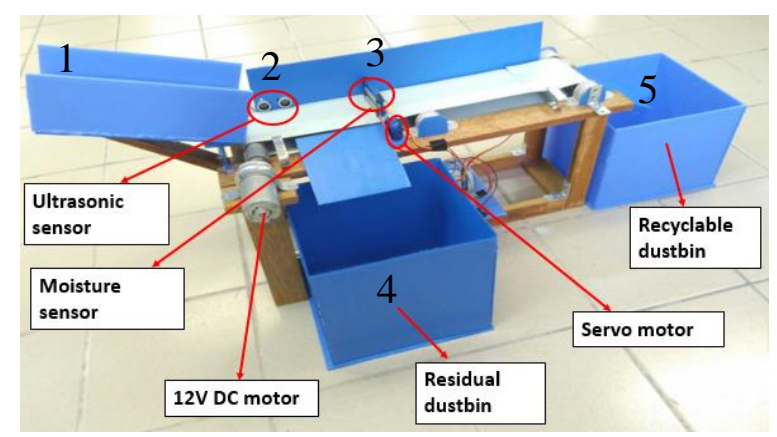

Figure 3. The prototype automatic household waste separation system

A waste is positioned onto the conveyor belt (point 1) and is moved by the DC motor until it reaches the ultrasonic sensor (point 2). Referring to the flowchart in Figure 4, the ultrasonic sensor will detect the presence of the waste by setting the distance in the Arduino coding with $\leq 7 \mathrm{~cm}$.

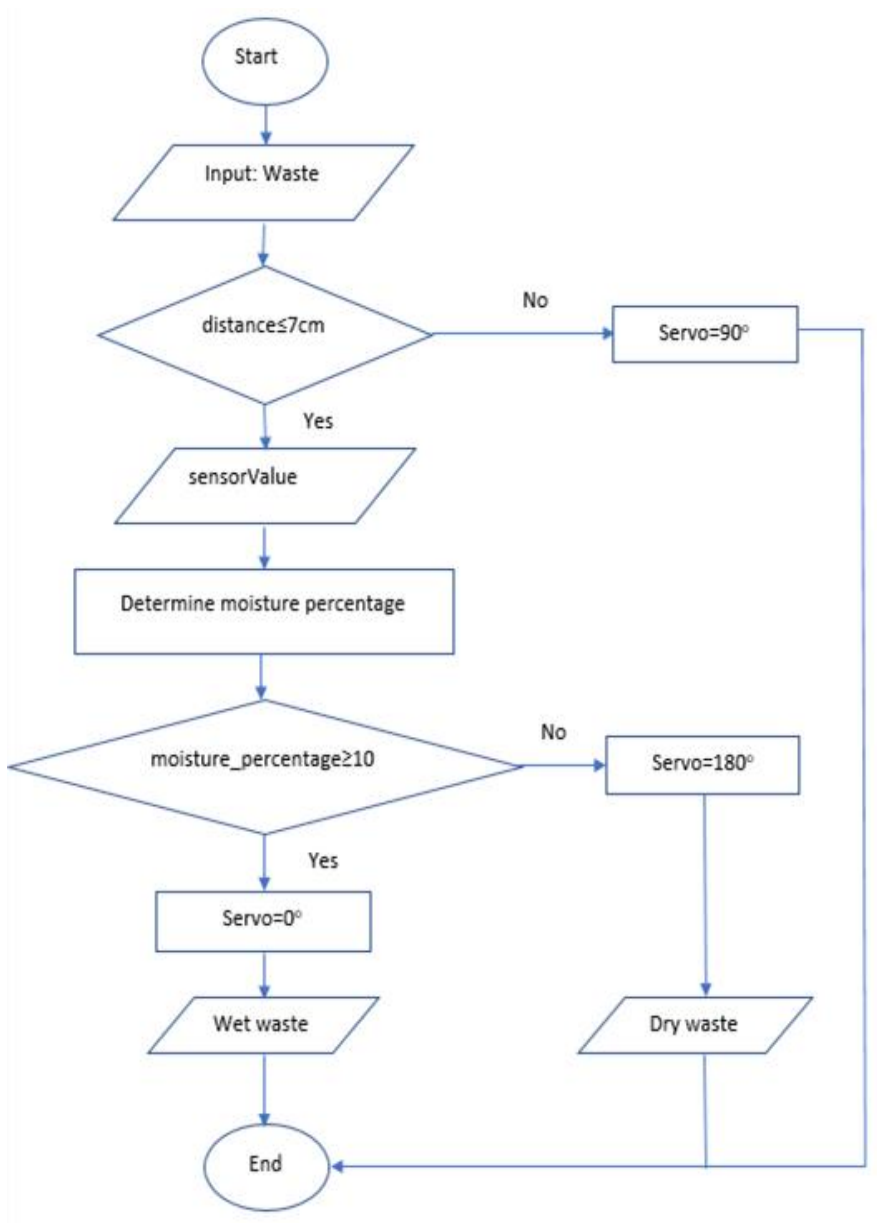

Figure 4. Flowchart of the prototype automatic waste separation system methodology 
Next, the servo motor and moisture sensor are attached together for them to work simultaneously. The position of the servo is initially set at $90^{\circ}$ when there is no waste placed on the conveyor belt. This means that the distance for the ultrasonic sensor is not $\leq 7 \mathrm{~cm}$. Once the ultrasonic sensor detects the presence of waste (point 2), the moisture sensor is ready to measure the value of resistance to the current of the waste. A delay is set about $7 \mathrm{~s}$ for the moisture sensor to measure the reading (i.e. $7 \mathrm{~s}$ is from the moment ultrasonic detect the presence of the waste). Delay is set because the moisture sensor need to be pressed quite hard for it to gain a more accurate value of electric conductivity of the current waste. For moisture sensor (point 3 ), it is set into two conditions:

a. If moisture percentage $\geq 10$; the particular waste is considered as wet waste (residual). For this condition, servo motor will rotate to $0^{\circ}$ and the waste is pushed into the residual dustbin (point 4 ).

b. If moisture percentage $\leq 10$; the particular waste is considered as dry waste (recyclable). For this condition, servo motor will rotate to $180^{\circ}$ and the waste continued to stay on the conveyor belt until it reach to the end and entered the recyclable dustbin (point 5).

Figure 5 shows the schematic diagram for the circuit which was used to operate the system. All the components; moisture sensor, ultrasonic sensor and servo are connected onto the Arduino Uno board, and the coding from Arduino software is uploaded into the board.

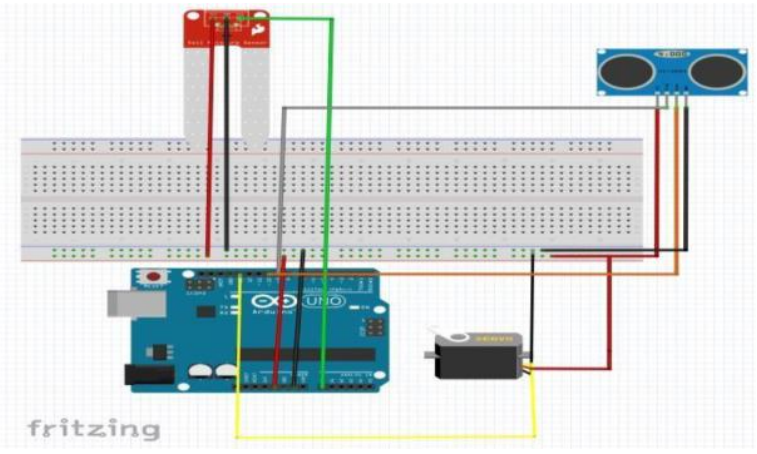

Figure 5. Schematic diagram of the circuit using Fritzing

\section{RESULTS AND ANALYSIS}

Initially, the measurement is conducted by testing the moisture sensor with water to obtain its resistance value, which is essential to measure the water content in the waste. Figure 6(a) shows how the moisture sensor is used to obtain the reading of the water. On the other hand, Figure 6(b) shows the resistance value $(\Omega)$ and percentage of moisture content $(\%)$ of the water taken from the Arduino Uno software. The reading is taken for several times and the average value is calculated. As a result, the average resistance value of water is measured to be $544 \Omega$, while the average percentage of moisture content is $46.75 \%$.

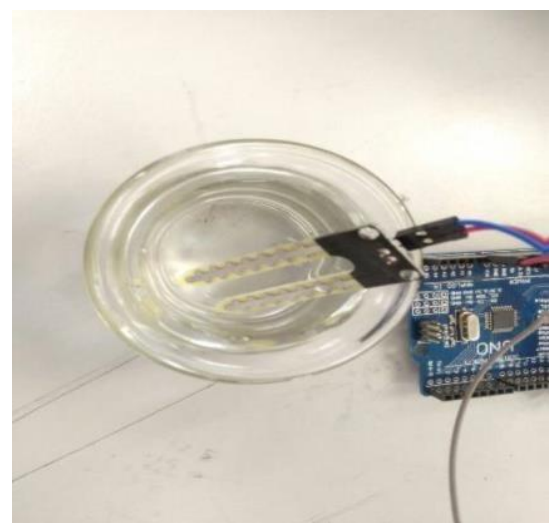

(a)

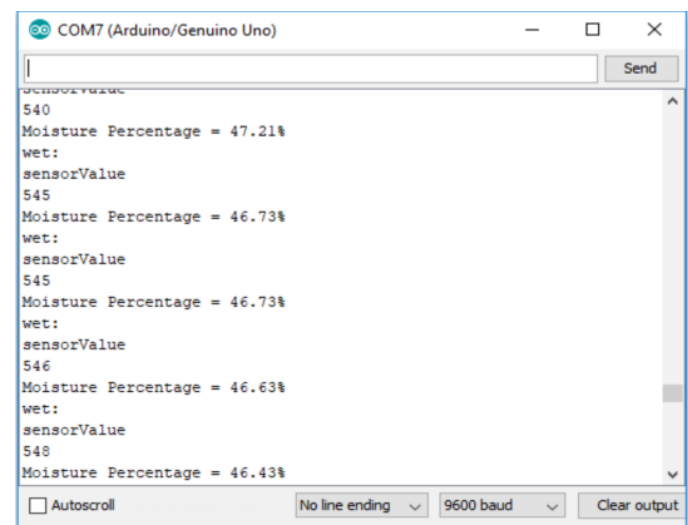

(b)

Figure 6. (a) Measurement of resistance value of water, (b) Resistance value $(\Omega)$ and percentage of moisture content of water $(\%)$ from Arduino software 
Next, the measurement is carried out to test a dry material. Figure 7(a) shows how the wood is measured using moisture sensor to get the resistance reading. Figure $7(\mathrm{~b})$ shows the resistance value $(\Omega)$ and percentage of moisture content $(\%)$ of the wood. Since the reading varies, the average reading is taken. The average resistance value of wood is measured to be $1022 \Omega$, while the average percentage of moisture content is $0.10 \%$.

The measurement is further carried out by measuring six other materials (wastes). Table 1 shows the experimental results of eight types of material which consist of water, onion, rose apple, cake, tin, plastic bottle, glass and wood. The table also shows the resistance value $(\Omega)$ and the percentage of moisture content $(\%)$ of the respective material.

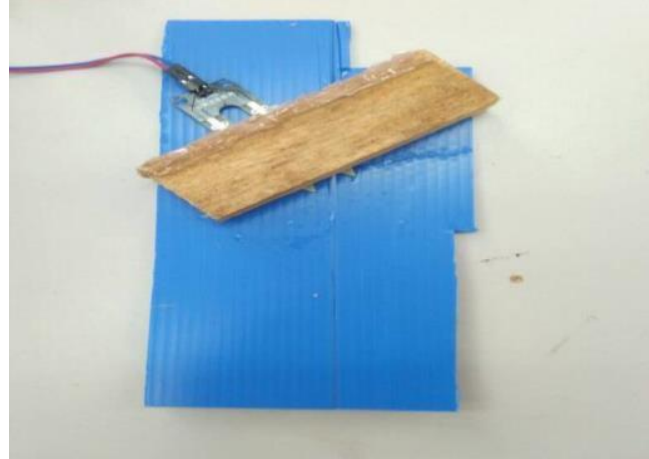

(a)

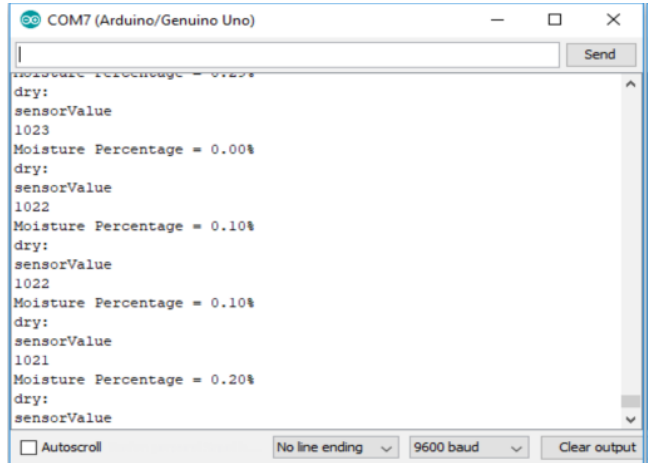

(b)

Figure 7. (a) Measurement of resistance value of wood, (b) Resistance value $(\Omega)$ and percentage of moisture content of wood $(\%)$ from Arduino software

Table 1. Experimental result based on resistance $(\Omega)$ and percentage of moisture content $(\%)$

\begin{tabular}{cccc}
\hline Material (Waste) & Resistance $(\Omega)$ & Percentage of moisture content $(\%)$ & State of material (waste) \\
\hline Water & 544 & 46.75 & Wet \\
Onion & 320 & 68.77 & Wet \\
Rose apple & 618 & 38.05 & Wet \\
Cake & 442 & 56.84 & Wet \\
Tin & 1012 & 1.12 & Dry \\
Plastic bottle & 1023 & 0.00 & Dry \\
Glass & 1019 & 0.39 & Dry \\
Wood & 1022 & 0.10 & Dry \\
\hline
\end{tabular}

It can be observed that the dry wastes (tin, plastic bottle, glass and wood) have a high resistance, between $1012 \Omega-1023 \Omega$, compared to wet wastes (water, onion, rose apple and cake), which varies between $320 \Omega-618 \Omega$. Meanwhile, the percentage of moisture content $(\%)$ is obtained from the resistance value of the waste. It is shown that wet wastes (water, onion, rose apple and cake) have high moisture content, between 38.05-68.77\% compared to dry waste (tin, plastic bottle, glass and wood), ranging between 0-1.12\%. In order to get the percentage of moisture content in the waste, (1) has been used and included in the coding;

Moisture_percentage $=(100-(($ sensorValue/1023.00)*100) $)$

The sensorValue represents the value of resistance to the current of the waste. The relationship of the resistance and percentage of water content can be related by; the higher the resistance, the lower the percentage of water content. It can be concluded that the resistance will be low if the moisture content of the waste is high, and thus more current will pass through it. On the other hand, when the water content is low, the resistance will be at high level.

Through this experiment, it is proved that when the samples of wet waste (water, onion, rose apple and cake) are placed onto the prototype system, the servo motor rotated to $0^{\circ}$ and the waste is pushed into the residual dustbin (point 4). This is because the moisture sensor detected a moisture content percentage of $\geq 10$ (i.e. 38.05-68.77\%). On the other hand, when the samples of dry waste (tin, plastic bottle, glass and wood) are placed onto the prototype system, the servo motor rotated to $180^{\circ}$ and the waste continued to stay on the conveyor belt until it reach to the end and entered the recyclable dustbin (point 5). This is due to the moisture sensor that detects a moisture content percentage of $\leq 10$ (i.e. $0-1.12 \%$ ). Therefore, it can be concluded that the prototype system are able to discriminate waste into residual and recyclable waste automatically. 


\section{CONCLUSION}

An approach for automatic separation of residual (wet) and recyclable (dry) waste was successfully achieved using a moisture sensor as the fundamental element of the system. The condition of the waste is decided based by its resistance to current value and percentage of water content [14]. Nevertheless, there are still a room for improvement for the proposed design that can embellish the accomplishment of the automated system and to prevent any possible deficiencies. First, it is recommneded that other sensors than the one used for this particular project i.e. moisture sensor and ultrasonic sensor shall also be implemented. Next, this system can also be improvised by using more sensitive sensors where it can discriminate the waste precisely according to its category: residual (wet) and recyclable (dry). Apart from that, the system can be further improvised where the recyclable (dry) waste can be categorized into paper, glass, plastic and metal by capturing the characteristics of the waste item, such as weight and size [15], and later a system to separate the metal recyclable household waste automatically into non-metal, steel, copper and aluminum metal waste and record the data waste collected [16]. This fully automated system is expected to reduce the poor quality effect towards both the surroundings and atmosphere, and also the community who are involved directly during the waste sorting. Without doubt, this proposed system will contribute hugely to the whole community and environment in this field.

\section{ACKNOWLEDGEMENTS}

This research was supported by International Islamic University Malaysia (IIUM) and Ministry of Education Malaysia (MOE) through Fundamental Research Grant Scheme (FRGS17-038-0604).

\section{REFERENCES}

[1] Y. X. D. Cruz, J. A. P. Chirva, and E. R. L. Santana, “A Mixed Integer Optimization Model to Design a Selective Collection Routing Problem for Domestic Solid Waste," Workshop on Engineering Applications - International Congress on Engineering (WEA), 2015.

[2] M. D. M. Samsudin and M. Mat Don, "Municipal Solid Waste Management in Malaysia : Current Practices, Challenges and Prospects," Jurnal Teknologi, vol. 62, no. 1, 2014.

[3] K. Sujatha, Siddappaji, and R. C. Radha "Technologies for Segregation and Management of Solid Waste : A review," International Conference on Emerging Trends in Engineering, Technology and Science (ICETETS), 2016.

[4] P. Sukholthaman and K. Shirahada, "Evaluation of Self-Service Technology on Household Waste Management in Emerging Countries : A Case of Bangkok, Thailand," Portland International Conference on Management of Engineering and Technology (PICMET), 2015.

[5] A. Chandramohan, J. Mendonca, N. R. Shankar, N. U. Baheti, N. K. Krishnan, and M. S. Suma, "Automated Waste Segregator," Texas Instruments India Educators' Conference (TIIEC), pp. 1-6, 2014.

[6] N. Sivakumar, A. R. Kunwar, S. K. Patel, S. Kumar and S. P. Mala, "Design and development of an automatic clustered, assorted trash segregation system," 2016 IEEE International Conference on Recent Trends in Electronics, Information \& Communication Technology (RTEICT), Bangalore, 2016, pp. 409-413.

[7] R. Rajkamal, V. Anitha, P. G. Nayaki, K. Ramya and E. Kayalvizhi, "A novel approach for waste segregation at source level for effective generation of electricity-GREENBIN," 2014 International Conference on Science Engineering and Management Research (ICSEMR), Chennai, 2014, pp. 1-4.

[8] B. M. Chinnathurai, R. Sivakumar, S. Sadagopan and J. M. Conrad, "Design and implementation of a semi-autonomous waste segregation robot," SoutheastCon 2016, Norfolk, VA, 2016, pp. 1-6.

[9] C. L. Fernandes, G. B. Gonsalves, D. D. Dessai, D. S. Lotlikar, S. Cardoso, and D. Bosco, "Moisture Sensing Unit for Waste Sorter Machine," IJSRD (International Journal for Scientific Research and Development). vol. 4, no. 11, pp. 557-560, 2017.

[10] M. H. Abd Wahab, A. Abdul Kadir, M. R. Tomari, and M. H. Jabbar, "Smart Recycle Bin: A Conceptual Approach of Smart Waste Management with Integrated Web Based System," International Conference on IT Convergence and Security (ICITCS), 2014.

[11] M. Sejera, J. B. Ibarra, A. S. Canare, L. Escano, D. C. Mapanoo and J. P. Suaviso, "Standalone Frequency Based Automated Trash Bin and Segregator of Plastic Bottles and Tin Cans," 2016 IEEE Region 10 Conference (TENCON), Singapore, 2016, pp. 2370-2372.

[12] P. Reis, R. Pitarma, C. Gonçalves, and F. Caetano, "Intelligent System for Valorizing Solid Urban Waste," $9^{\text {th }}$ Iberian Conference on Information Systems and Technologies (CISTI), 2014.

[13] A. D. Mengistu and D. M. Alemayehu, "Soil Characterization and Classification: A hybrid Approach of Computer Vision and Sensor Network," International Journal of Electrical and Computer Engineering, vol. 8, no. 2, 2018.

[14] N. N. Ahamad, S. Y. Mohamad, N. S. Midi, S. H. Yusoff, and F. Abd Rahman, "Discrimination of Residual and Recyclable Household Waste for Automatic Waste Separation System," $7^{\text {th }}$ International Conference on Computer and Communication Engineering (ICCCE), pp. 372-374, 2018.

[15] M. A. Rahmad, N. S. Midi, S. A. Zaini, S. H. Yusoff and S. Y. Mohamad, "Material Classification of Recyclable Waste using the Weight and Size of Waste," $7^{\text {th }}$ International Conference on Computer and Communication Engineering (ICCCE), pp. 44-49, 2018. 
[16] S. Mahat, S. H. Yusoff, S. A. Zaini, N. S. Midi, and S. Y. Mohamad, "Automatic Metal Waste Separator System in Malaysia," $7^{\text {th }}$ International Conference on Computer and Communication Engineering (ICCCE), pp. 366-371, 2018.

\section{BIOGRAPHIES OF AUTHORS}
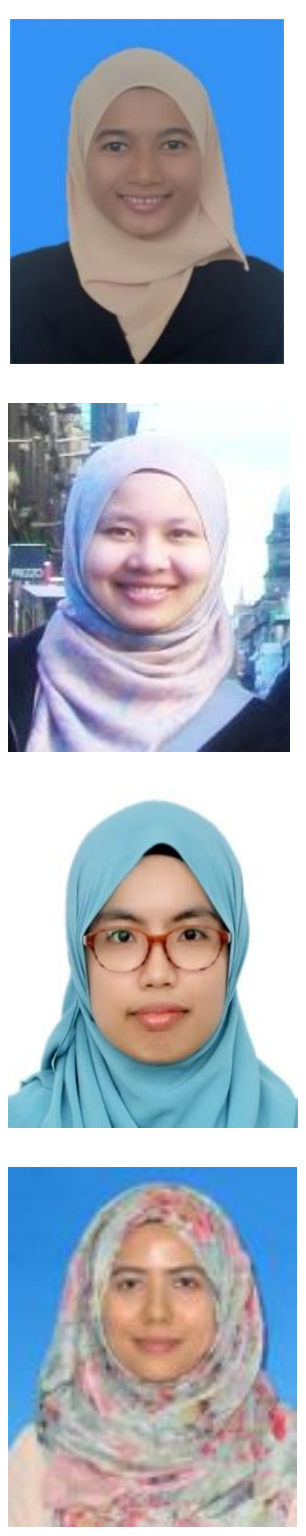

Siti Hajar Yusoff received a MEng. Degree $\left(1^{\text {st }}\right.$ Class Hons) in Electrical Engineering from the University of Nottingham, UK and a Ph.D. degree in Electrical and Electronic Engineering from the University of Nottingham, U.K., in 2009 in 2014, respectively. She has been appointed as an Assistant Professor in the Department of Electrical and Computer Engineering, Faculty of Engineering, International Islamic University Malaysia (IIUM). Her current research interests include IoT (Internet of Things), Smart cities, non-linear control, renewable energy, wireless dynamic charging in electric cars.

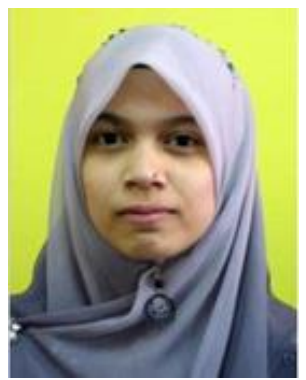

Faridah Abd Rahman received a BEng in Electrical and Electronics Engineering from Yamaguchi University, Japan, in 2010. She obtained a MEng in Electronics System from the same university in 2012, and a Ph.D degree from Universiti Teknologi Malaysia (UTM), Malaysia in 2017. She is currently an Assistant Professor in the Department of Electrical and Computer Engineering, Kulliyyah of Engineering, International Islamic University Malaysia (IIUM). Her current research interests include biomedical signal processing and health monitoring system. 